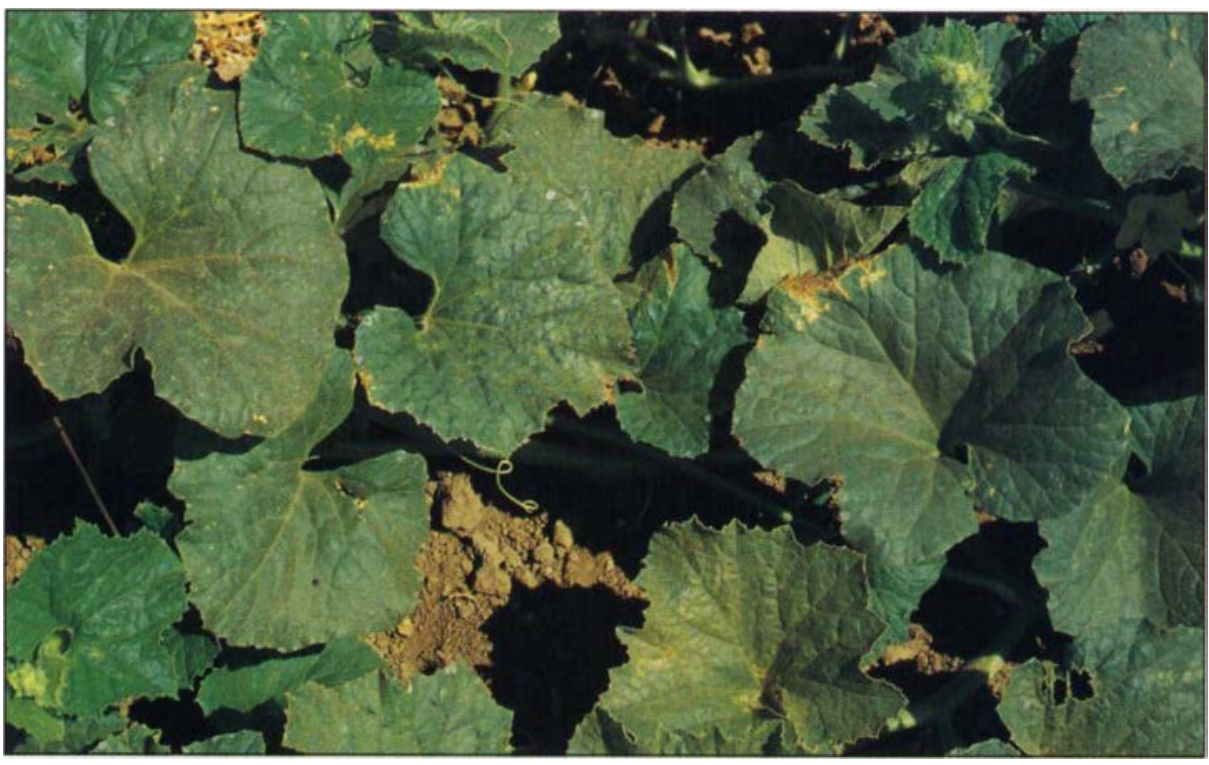

Leaves of honeydew melon plants infected with watermelon mosaic virus showing light and dark green mosaic symptoms.

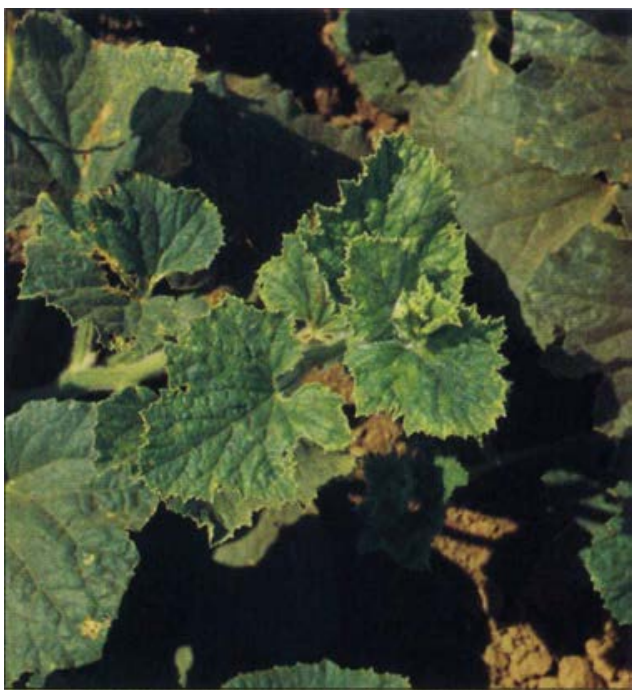

Honeydew melon plants infected with cucumber mosaic virus showing yellow and green mosaic symptoms along with slight puckering of leaves. Infected plants usually appear stunted.

\title{
Stylet oil provides limited control of aphid-transmitted viruses in melons
}

\author{
Kodira C. Umesh $\square$ Jesus Valencia $\square$ Chase Hurley $\square$ W. Douglas Gubler $\square$ Bryce W. Falk
}

\begin{abstract}
Aphid-borne viruses pose a significant threat to California melon growers. Insecticides can kill aphids, but do not prevent the rapid virus transmission. In seven field trials conducted in Davis and the Central Valley, we studied the efficacy of JMS Stylet Oil in reducing the spread and incidence of aphid-transmitted viruses. Stylet oil reduced the incidence and spread of aphid-transmitted viruses when inoculum pressure was low. However, when inoculum pressure was high, the oil did not reduce virus spread to tolerable levels, but delayed initial infection to some degree.
\end{abstract}

One of the most significant threats to California melon growers is the spread of aphid-borne virus disease. Melons are grown in the Sacramento and San Joaquin valleys in the spring and summer, and only in the spring in the Imperial and Palo Verde valleys. For several years, virus diseases have caused problems in most production regions. The most common and economically important viruses affecting cantaloupe and mixed melons are watermelon mosaic potyvirus (WMV) and cucumber mosaic cucumovirus (CMV) in the north; and zucchini yellow mosaic potyvirus (ZYMV) in desert production areas. Squash mosaic comovirus (SqMV) and the recently discovered cucurbit aphid-borne yellows luteovirus (CABYV) also occur throughout California, but with less frequency. In all cases, the incidence and severity of these viruses are largely unpredictable.

Three of the viruses - WMV, $C M V$, and $Z Y M V$ - are spread from plant to plant by several species of aphid in a non-persistent manner. The virus CABYV, on the other hand, is transmitted in a persistent but nonpropagative manner primarily by the cotton-melon aphid, Aphis gossypii, and the green peach aphid, Myzus persicae. The virus SqMV can be seedborne but is usually transmitted from plant to plant by the spotted cucumber beetle, Diabrotica sp.
Because these viruses are spread by insects, growers have attempted to control the spread of disease by controlling insect vectors with insecticides. This strategy has had limited success, but generally is not effective against non-persistently transmitted viruses. Many species of aphids can transmit viruses such as WMV, CMV and ZYMV in a matter of seconds simply by probing or sampling a plant. Insecticides such as endosulfan (Thiodan $3 \mathrm{EC})$ can control aphid colonization, but cannot kill the aphids before they transmit the virus to the plant.

Dilute mineral-type oil sprays were first used against non-persistent aphid transmission of viruses in 1962. Although these sprays do not directly affect the aphid vector, as insecticides do, they appear to interfere with the spread of the virus from an infected plant to a healthy one. However, the success of various mineral-type oil sprays has been inconsistent. We evaluated the effectiveness of JMS Stylet Oil (JMS Flower Farms, Inc., Vero Beach, Florida) in controlling WMV and CMV on honeydew melons 


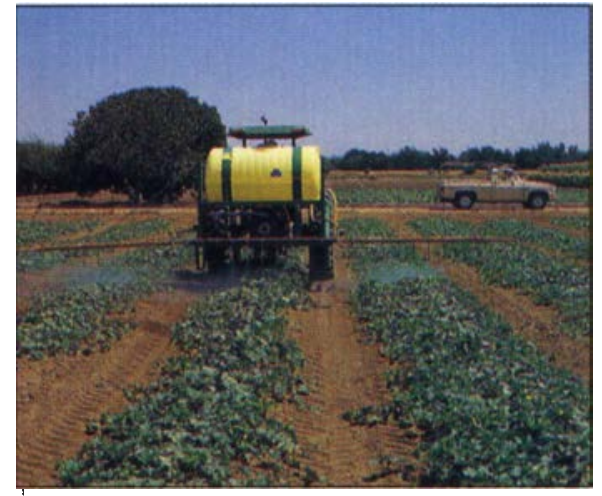

Tractor-mounted sprayer with nozzles designed for dispensing reduced droplet size under high pressure (400-450 psi).

under high and low disease-pressure situations.

\section{Disease monitoring}

Three trials were conducted at UC Davis, and four trials on growers' fields in the Central Valley. Plot sizes at Davis were 3 acres for the first two trials and 6 acres for the third trial. The plots in the Central Valley included two in Stanislaus County and one each in Merced and Fresno counties. These plots ranged in size from 3 to 6 acres. Sprayed and unsprayed areas at both sites were 0.5 acres in size, and replicated three times in a randomized block design. The experiments were conducted from the end of April to the middle of October 1993, with the exception of one trial in Stanislaus County, which was conducted from June to August of 1992.

To treat the crops, we used tractormounted sprayers with a 3-point hitch and spray bar, with nozzles designed for dispensing reduced-size droplets under high pressure (400 to 450 psi). The spray bar spanned three rows of plants, with nozzles placed about 10 inches apart and directed toward the plants. To maintain thorough coverage of the plant canopy, we increased the number of nozzles from three to seven per row as the plants grew. Stylet oil was sprayed at the rate of $0.75 \%$ at 450 psi, with tractor speed varying from 3 to $3.5 \mathrm{mph}$. Beginning at $50 \%$ emergence, plants were sprayed every third day at Davis and twice a week in growers' fields in the Central Valley. Spraying was done early in the morning on cool days and late in the evening on warm days to avoid phytotoxicity.

To simulate a situation of high disease pressure at Davis, we transplanted $600 \mathrm{CMV}$-infected plants and 600 WMV-infected plants around the field perimeter for the first two trials, but not for the third. In the Central Valley, we relied upon natural virus inoculum. Aphid populations were monitored by pan traps set in the four corners of each field. The aphids were collected weekly and their numbers averaged to come up with a weekly mean. We monitored fields every 7 to 10 days, then mapped virus infection in the plots. Visual observations of virus infection were confirmed by enzyme-linked immunosorbent assay (ELISA) in the laboratory. The treatment differences in percent infection were analyzed by analysis of variance and $\mathrm{t}$-test.

\section{Virus and aphid incidence}

In the first trial at Davis, plots sprayed with stylet oil had a lower percentage $(P \leq 0.05)$ of infected plants than the unsprayed control plots 73 days after planting. At 57 and 66 days after planting, the difference was significant only at $P=0.10$ (fig. 1A). Plots sprayed with stylet oil had about $52 \%$ infection, compared to $69 \%$ infection for unsprayed plots 73 days after planting. The high levels of infection may have been due to high disease pressure in the field as well as the disruption of two spray treatments due to rain June 5 and 6,1993 , when the plots were not sprayed for a period of 6 days.

In the second trial, the virus incidence and rate of spread was much higher, with virtually no difference $(P=0.05)$ observed between sprayed and unsprayed plots (fig. 1B). Ninetythree percent of plants in the sprayed plots and $95 \%$ of plants in unsprayed plots were infected about 50 days after planting. Inoculum pressure was extremely high as virus-infected plants from the first trials were still present in the adjacent plot.

In the third trial, no CMV or WMVinfected plants were transplanted around the field. As a result fewer plants were virus-infected. Sprayed plots had only $1.4 \%$ incidence of virus- infected plants, which was significantly lower $(P \leq 0.05)$ than the $12.8 \%$ incidence in the unsprayed plots.

Aphid counts averaged about 20-25 per trap per week during the early stages of the first two trials. In the third trial, we found only about five aphids per trap. The majority of those plants infected at Davis were infected by WMV.

In the Central Valley, where we relied only upon natural inoculum, three of the four trials showed no detectable virus incidence or significant aphid activity. In the fourth trial, beginning in July, the oil-treated plants had about $15 \%$ virus infection compared to $19 \%$ infection for those not treated (fig. 1C). Treatment did not appear to have an impact on virus incidence $(P=0.05)$.

In the earliest trial, conducted from July to August of 1992 in Stanislaus

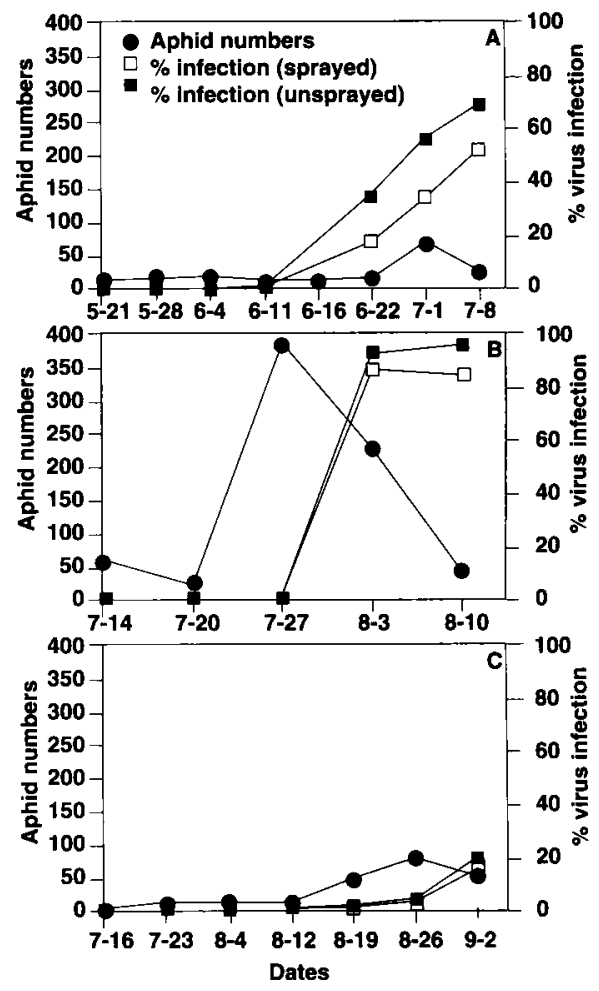

Fig. 1. Virus incidence and aphid numbers in honeydew melon plots sprayed with JMS Stylet Oil and in unsprayed plots. A, B. Percentage of plants infected with virus and mean aphid numbers in trials conducted under high inoculum pressure at UC Davis, during 1993. C. Virus incidence and mean aphid numbers in one of the four trials conducted in the California Central Valley during 1993. The plants were assessed visually for symptoms of virus infection, with accuracy of visual assessment confirmed by ELISA to be about 98-99\%. 
County, plants sprayed with stylet oil had about $10.4 \%$ virus infection, compared to about $13.3 \%$ for those not sprayed. Virus incidence in the two treatments was not statistically different $(P=0.05)$.

\section{Conclusion}

Virus spread was extremely rapid in the first two trials at Davis. Virus incidence increased from almost zero to about $35 \%$ in the first trial, and to about $80 \%$ in the second trial, just one week after symptoms were initially noticed.

Our observations and experiments indicate that low numbers of aphids are capable of causing a high level of disease if a source of virus inoculum is nearby. Viruses such as WMV and CMV are spread by non-colonizing aphids, so growers can't rely on visible evidence of aphids colonizing melon plants as an indication of infection.

Based on the results of our experiments, we concluded that JMS Stylet Oil is effective in reducing the incidence and spread of aphid-transmitted viruses when inoculum pressure is low. When inoculum pressure is high, the stylet oil appears to delay the initial infection by a few days but does not succeed in keeping the spread at tolerable levels. Researchers in Florida recently reported similar results.

Given these limitations, growers must decide for themselves whether application of JMS Stylet Oil is costeffective. The application of stylet oil requires a significant amount of labor and cost. Thorough coverage of plants is necessary at all times to prevent aphid virus transmission. This requirement may be difficult to meet given the rapid growth of melon plants during warm growing seasons.

K.C. Umesh is Postdoctoral Researcher, C. Hurley is Research Assistant, W.D. Gubler is Professor and Extension Pathologist, and B.W. Falk is Professor, all in the Department of Plant Pathology, UC Davis; and J. Valencia is Farm Advisor, UC Cooperative Extension, Stanislaus County.

We thank the California Melon Research Board for funding part of this study.

\title{
Efforts to reduce stratospheric ozone loss affect agriculture
}

\author{
Bryan C. Weare
}

\begin{abstract}
Research has shown that the increased ultraviolet radiation reaching the Earth's surface resulting from stratospheric ozone loss poses a danger to everyone. Concern about ozone loss prompted many nations to ratify the Montreal Protocol, the most comprehensive international environmental agreement ever enacted. Several provisions of this protocol will have substantial, long-term effects on the agricultural industry. Agriculture contributes substantially to ozone depletion, primarily through its use of chlorofluorocarbons (CFCs) for refrigeration in processing, storage and transport of meats and produce. This paper is meant to serve as an overview of the scientific basis for ozone depletion concerns, a description of the current international policy agreement, and the possible consequences of that policy for agriculture.
\end{abstract}

Ozone is a rare form of oxygen that is composed of three $\left(\mathrm{O}_{3}\right)$ rather than two atoms $\left(\mathrm{O}_{2}\right)$ as is true of the vast majority of oxygen in the atmosphere. Ozone exists primarily in two distinct layers of the atmosphere: in the bottom mile, especially in urban regions, and 15 to 30 miles above ground in the stratosphere. Ozone in the lower level is the most important form of urban air pollution and might be labeled "bad" ozone because it contributes to respiratory and other health problems and increased concentrations may lead to decreased crop yields. The second layer is much thicker and is essential to all life as the primary absorber of dangerous ultraviolet radiation from the sun's rays. This might be called the "good" ozone. This report will only be concerned with this stratospheric ozone layer.

\section{Stratospheric ozone depletion}

The basics of the science of stratospheric ozone and its depletion by chlorofluorocarbons (CFCs) are illustrated schematically in figure 1 . Good ozone is continually created and destroyed by a number of complex chemical reactions. The ultimate source of the ozone is the simple reaction $\mathrm{O}_{2}+\mathrm{O}=\mathrm{O}_{3}$; the oxygen atom $\mathrm{O}$ is formed when the sun's ultraviolet radiation breaks apart an oxygen molecule $\mathrm{O}_{2}$. The ultimate loss of ozone is through nearly the opposite reaction $\mathrm{O}_{3}+\mathrm{O}=2 \mathrm{O}_{2}$ that results in regular oxygen molecules again. The actual processes are considerably more complicated, involving catalysts which help speed production or destruction. Without human intervention, the production and destruction processes result in a relatively fixed amount of ozone, much like a bathtub would remain at a constant level if the amount of water flowing from the tap exactly equaled the amount going down the drain .

Human intervention does occur and affects the amount of ozone in the stratosphere. Ozone depletion is primarily due to the introduction of large quantities of chlorine- and brominecontaining molecules into the stratosphere. The most important are re- 